\title{
Prognostic Relevance of SFRP1 Gene Promoter Methylation in Colorectal Carcinoma
}

\author{
Alok Kumar ${ }^{1,2}$, Sunil Babu Gosipatala ${ }^{1}$, Anshuman Pandey ${ }^{3}$, Pradyumn Singh ${ }^{2 *}$
}

\begin{abstract}
Background: The development of colorectal carcinoma (CRC) involves many genetic and epigenetic alterations and methylation being an important epigenetic event has been described as a diagnostic and prognostic biomarker. Secreted Frizzled- Related Protein 1 (SFRPI) gene regulates diverse physiological processes via the Wnt signaling. Promoter hypermethylation of $S F R P 1$ gene is an epigenetic regulation mechanism that downregulates $S F R P 1$ protein level in the tumor, and happens to be one of the significant events in colorectal carcinogenesis. We studied the clinicopathological relationship of CRC including survival outcomes with SFRP1 gene promoter methylation. Methods: We evaluated promoter methylation status of SFRP1 gene by methylation-specific PCR (MS-PCR) in the tumor tissue in 54 cases of stage II-III CRC patients in north India. The MS-PCR result was further validated by bisulfite sequencing. Results: SFRP1 gene was methylated in $72.2 \%$ cases and un-methylated in $27.8 \%$. We found, that SFRP1 gene methylation in tumor was associated with lymph node invasion $(\mathrm{p}=0.05)$. The mean overall survival was 22.318 months and 45.173 months respectively for patients with methylated and unmethylated $S F R P 1$ gene ( $\mathrm{p}=0.010, \log$ rank test), $(\mathrm{HR}=17.313$, 95\% CI: 2.021-148.290 P=0.009). Conclusion: Study indicates that promoter methylation of $S F R P 1$ gene is associated with lymph-node metastasis and poor mean overall survival and it can be a prognostic marker in CRC.
\end{abstract}

Keywords: Colorectal carcinoma- Methylation Specific PCR (MS-PCR)- Promoter hypermethylation,- SFRP1 gene

Asian Pac J Cancer Prev, 20 (5), 1571-1577

\section{Introduction}

Colorectal carcinoma (CRC) is one of the leading causes of mortality worldwide. It is the third most common cancer in males and second in females globally and recorded as second major cause of cancer-related deaths worldwide (Bray et al., 2018). In India CRC is fifth most common cancer in females and forth in males with incidence rate of $3.1 \%$ and $5.8 \%$ respectively (Bray et al., 2018). There is an increasing incidence of CRC in India. CRC is a heterogenous disease, influenced by genetic and epigenetic alterations and the heterogenicity is due to several pathways involved in CRC tumorigenesis (Colussi et al., 2013). CRC patients show a significant difference in prognosis and individual treatment responses even when presenting at same clinical stage. Multiple factors deregulate the expression of cancer related genes (like APC, KRAS, BRAF, TP53, SFRPs MLH1, MSH1) and promoter methylation mediated silencing is one of them (Armaghany et al., 2012; Thiel et al., 2013; Fearon and Vogelstein, 1990; Wheeler et al., 2000). Secreted Frizzled Related Protein1 (SFRP1) gene is known for its ability to negatively modulate the Wnt signaling cascade (Mii and Taira, 2011). SFRP1 gene codes for SFRP1 protein that works as an antagonist of Wnt protein and plays a significant role in the regulation of $\mathrm{Wnt} / \beta$ catenin signaling pathway. $\beta$-catenin dependent canonical WNT signaling maintains crypt stem cell compartment in the intestine but overactivation of this pathway by genetic or epigenetic changes has been seen in colorectal carcinoma (Novellasdemunt et al., 2015). This Wnt/ $\beta$ catenin pathway also plays important role in tumorigenesis of several other types of cancers like breast, ovarian, gastrointestinal cancer (Clevers and Hans, 2006; Huang et al., 2006; Zhan et al.,2006). In CRC, SFRP1 gene expression is found to be downregulated due to aberrant methylation in its promoter region and this promoter methylation is a common epigenetic alteration found in human cancers including colorectal carcinoma (Suzuki et al., 2004; Jones and Jomary, 2002). CpG islands are susceptible for methylation and since most of gene promoter regions are $\mathrm{CpG}$ island rich, it implies that promoter regions are most susceptible for hypermethylation and thus, promoter methylation leads transcriptional silencing of the gene (Nandakumar et al., 2011). If promoter hypermethylation occurs in tumor suppressor gene it may lead to tumorigenesis. Promoter hypermethylation mediated epigenetic silencing of SFRP1 gene is a major

${ }^{1}$ Department of Biotechnology, Babasaheb Bhimrao Ambedkar University, ${ }^{2}$ Department of Pathology, ${ }^{3}$ Department of Surgical Gastroenterology, Dr Ram Manohar Lohia Institute of Medical Sciences, Lucknow, India. *For Correspondence: drpsingh.path@gmail.com 
cause of downregulation of SFRP1 protein level and leads overactivation of Wnt signaling in CRC. Methylation based molecular makers are successfully being used in routine as prognostic/predictive marker for better patient management in various cancer Eg. MGMT in Gliomas (Weller et al., 2010). Some studies have also described value of SFRP1 as prognostic/predictive biomarker in cancer (Leygo et al., 2017; Zheng et al., 2015). The aim of our study was to look for promoter hypermethylation of SFRPl gene in CRC, and find its prognostic significance. It explores for association of promoter methylation of SFRP1 gene with clinicopathological features of CRC and patient survival.

\section{Materials and Methods}

\section{Patients and tissue specimen}

We enrolled 54 histopathologically confirmed cases of CRC, who underwent curative surgery in Departments of Surgical Gastroenterology and Surgical Oncology, Dr. R M L Institute of Medical Sciences Lucknow, UP, India. Of these 54 cases $28(51.85 \%)$ case were stage II and 26 $(48.15 \%)$ cases were stage III at the time of diagnosis (Lippincott-Raven et al., 1998). After histopathological examination (HPE), the FFPE tissue blocks were taken for molecular analysis. HPE (staging and grading) were done by standard procedure. Patient demographic and histopathological details and follow up were recorded. This study was approved by Institutional Ethics Committee (IEC no-8/15) of Dr. RMLIMS, Lucknow, and written informed consent was taken for all cases included in this study. The selection of tumor and non-tumor regions was done by examining Hematoxylin - Eosin (H and E) stained sections. Patient follow up and mean survival was noted up to the close of study observations (July 2018) or the death of the patient which was earlier.

\section{Genomic DNA extraction}

DNA extraction from FFPE tissues were done by using QIAamp FFPE tissue Kit, REF no. 56404 (Qiagen, Hilden, Germany) by following manufacturer's protocol. DNA quality and quantity checked by spectrophotometrically. Purity and integrity checked by agarose gel electrophoresis in $0.8 \%$ agarose gel.

\section{Bisulfite modification of DNA}

The genomic DNA isolated from the CRC tumor and adjacent normal tissue were subjected to bisulfite methylation analysis. Bisulfite conversion of DNA was done by using Epitect Bisulfite kit (Cat No./ID: 59104 Qiagen, Hilden, Germany) by following manufacturer's protocol designed for processing DNA isolated from FFPE tissue samples. Briefly, the $20 \mu 1$ solution of DNA(500ng$2 \mu \mathrm{g}$ ) mix with $35 \mu \mathrm{l}$ of DNA protecting buffer and $85 \mu \mathrm{l}$ bisulfite mix and incubated for conversion in thermo cycler at recommended temperature. After completion of bisulfite conversion reaction, $310 \mu \mathrm{l}$ freshly prepared buffer BL containing $10 \mu \mathrm{g} / \mathrm{ml}$ carrier RNA (Carrier RNA increases binding of DNA to the spin-column membrane) added to sample then sample transferred to spin columns after that washing by wash buffer. Followed by desulphonation step performed by adding $500 \mu \mathrm{l}$ de-sulfonation buffer $\mathrm{BD}$ to the spin columns and incubate for $15 \mathrm{~min}$ at room temperature. Then sample twice washed by wash buffer. Then final bisulfite converted DNA eluted in $20 \mu$ l elution buffer. Bisulfited converted DNA used for MS-PCR analysis within 24 hours.

\section{Methylation specific PCR (MS-PCR)}

Methylation specific PCR was set up according to the method described by Herman et al., (1996). $2.5 \mu \mathrm{l}$ bisulfite converted DNA was amplified using methylation specific primers that specifically recognized either the unmethylated or methylated SFRP1 gene sequence after bisulfate conversion (Takada et al., 2004). Sequences of the primers for MS-PCR of the SFRP1 promoter region were commercially procured. The sequences for Methylated primer were Forward: 5'-TGTAGTTTTCGGAGTTAGTGTCGCGC-3', Reverse : 5' CCTACGATCGAAAACGACGCGAACG3' (126bp); unmethylated primers, Forward5'-GTTTTGTAGTTTTTGGAGTTAGTGTTGTGT-3', Reverse:5'CTCAACCTACAAATCAAAAACAACAC AAACA-3' (135bp). All PCR reactions were performed using AmpliTaq Gold PCR master mix PCR cycling conditions were as following: initial denaturation at $95^{\circ} \mathrm{C}$ for $10 \mathrm{~min}$ then 35 cycles consisting of three steps: $95^{\circ} \mathrm{C}$ for $10 \mathrm{~s}$, respective annealing temperature for $30 \mathrm{~s}$ at $59^{\circ} \mathrm{C}$, extension at $68^{\circ} \mathrm{C}$ for $10 \mathrm{~s}$ followed by a final extension at $72^{\circ} \mathrm{C}$ for $10 \mathrm{~min}$. The annealing temperature for amplification of methylated and un-methylated $S F R P 1$ promoter region was $59^{\circ} \mathrm{C}$, and $58^{\circ} \mathrm{C}$ respectively. Methylated and un-methylated bisulfite converted human control DNA procured from Qiagen, Hilden, Germany was used as positive control for methylation and unmethylation.

\section{SFRP1 Promoter methylation sequencing analysis}

Validation of MS-PCR results and methylation pattern of $\mathrm{CpG}$ in promoter region was done by bisulfite sequencing using the method defined by Susan et al., (1994). MS-PCR products from tumor and normal tissues were sequenced by using $\mathrm{ABI}$ sequencing platform Genetic analyzer 3500, and sequence analysis and alignment was done using Bioedit software and CLUSTALW online tool.

\section{Statistical analysis}

Statistical analyses was done by using SPSS software (version 20). Chi square test was used to analyze the statistical association between clinic-pathological data and methylation status of SFRP1. Kaplan Meier survival curve and Log-rank test were used for survival analysis. To evaluate the prognostic impact, all clinicopathologic variables were evaluated along with SFRP1 methylation status by using univariate cox proportional hazard model analysis. P-value $<0.05$ was considered as significant.

\section{Results}

\section{Clinicopathological characteristics}

The clinicopathological details are summarized in Table 1. The median age of patients at the time of 
(a)

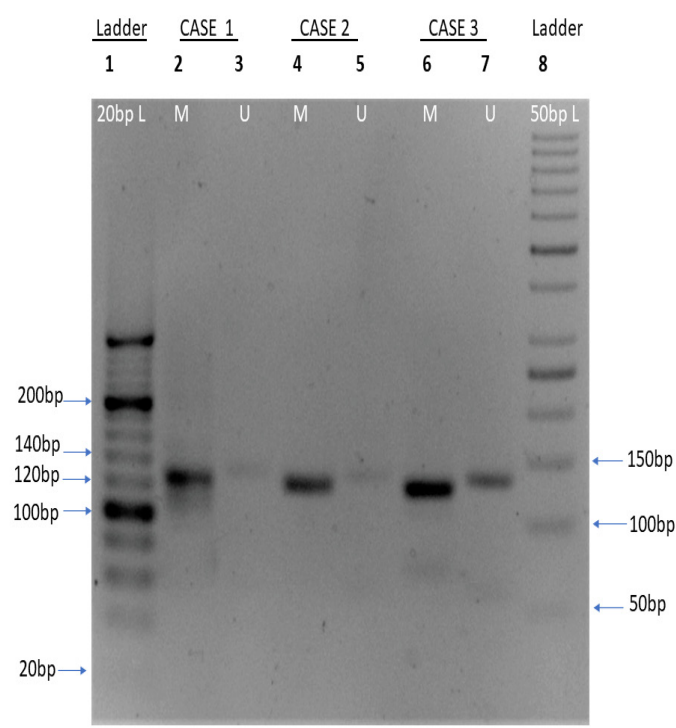

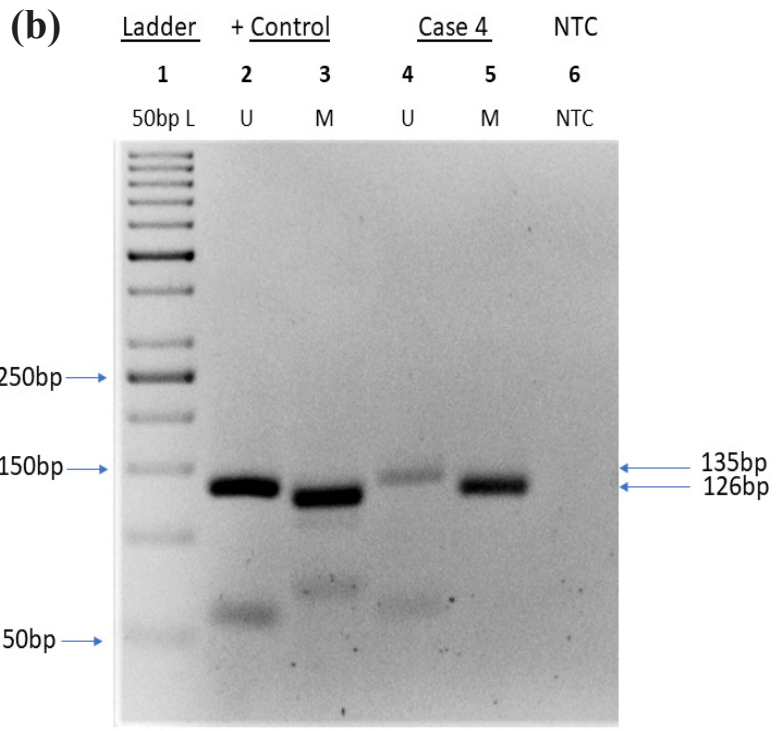

Figure 1. Promoter Methylation Analysis of SFRP1 Gene in CRC Tumor Tissue by Methylation Specific Polymerase Chain Reaction (MS-PCR). MS-PCR amplified product run in 4.0\% agrose gel. (a), Shows distinct band of methylated frgment in lane 2,4,6 and their intensity hingher than respective unmethylated band lane 3,5,7 in 3 Colorectal carcinoma tumour tissue. 20bp ladder in lane 1 and 50bp ladder in lane 8; (b), Shows the methylated DNA band in a CRC tumour tissue (lane 5) with control, positive control unmethylation (lane 2), positive control methyaltion (lane 3) and nigative control NTC ( lane 6) with $50 \mathrm{bp}$ ladder (lane 1). Size of Methylated and Un-methylated fragment is $126 \mathrm{bp}$ and $135 \mathrm{bp}$ respectively. $\mathrm{M}$ (Methylation specific polymerase chain reaction), $\mathrm{U}$ (Un-methylation specific polymerase chain reaction), L (Ladder) NTC (Non Templete Control, water used instead of DNA template.

diagnosis was 49 years (range 18-76 years). Of these 33 $(61.1 \%)$ were male and $21(38.9 \%)$ were female patients (M:F = 1.57:1). $28(51.85 \%)$ cases were of CRC stage II, and $26(48.15 \%)$ stage III. The tumor site was right colon in $18(33.3 \%)$, left colon (excluding rectum) in 20 (37\%) and rectum in $16(29.6 \%)$ cases. Histologically, 47 $(87 \%)$ tumors were infiltrating adenocarcinoma NOS, 7 (13\%) were mucinous adenocarcinoma. The tumor grade was well differentiated in 32 (59.3\%) cases, moderate differentiation in $13(24 \%)$ and poor differentiation in 9 $(16.6 \%)$ cases. Clinical follow up ranging from 12 to 56 months was available in these cases.

SFRP1 gene promoter methylation in tumor tissue

We analyzed $S F R P 1$ gene promoter methylation status in tumor tissue and adjacent normal tissue. In 39 out of 54 (72.2\%) CRC cases SFRP1 gene was methylated while in $15 / 54(27.8 \%)$ cases it was unmethylated. Whereas in only

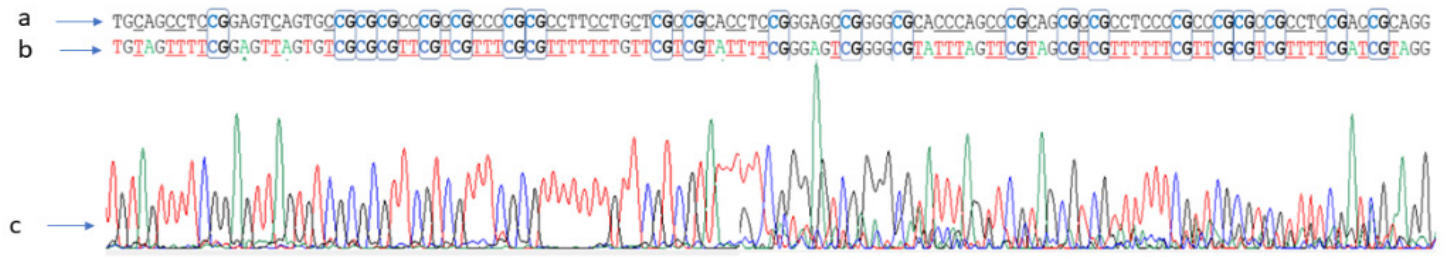

Figure 2a

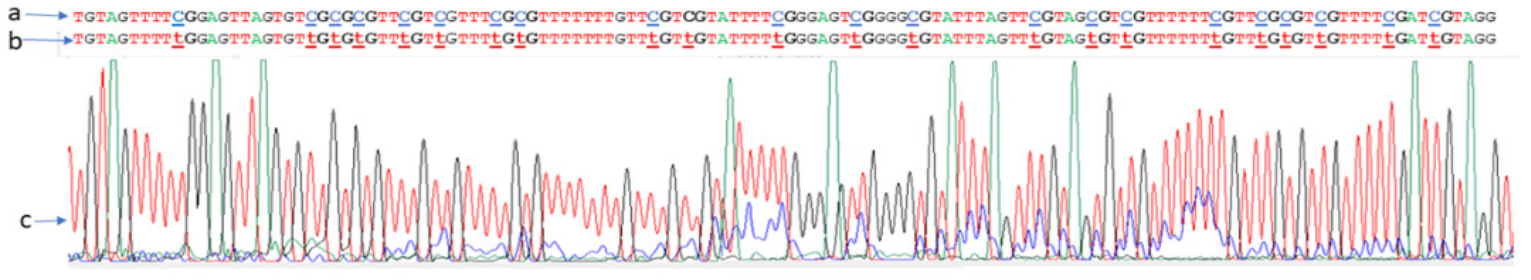

Figure $2 \mathrm{~b}$

Figure 2. SFRP1 gene promoter methylation analysis by bisulphite sequencing. (a), Chromatogram of methylated SFRP1 gene promote - Bold blue C represents methylated cytosine that's remained unchanged during bisulfite conversion due to its methylation and $\mathrm{C}$ represents un-methylated cytosine that converted to thymine represented $\mathrm{T}$, and $\mathrm{CG}$ in round corner rectangle represents CpG sites; (b), Chromatogram in a case of un-methylated SFRP1 gene $\mathrm{t}$ represented un-methylated cytosine that converted to thymine during bisulphite conversion. Arrow marked-"a" is sequence is normal 126bp of DNA sequence of SFRP1 gene of Homo sapiens SFRP1 gene (NCBI Reference Sequence: NM_003012.4), "b" Bisulfite converted DNA sequence of methylated SFRP1 gene of CRC case "c" chromatogram of bisulfite sequencing 
(a)

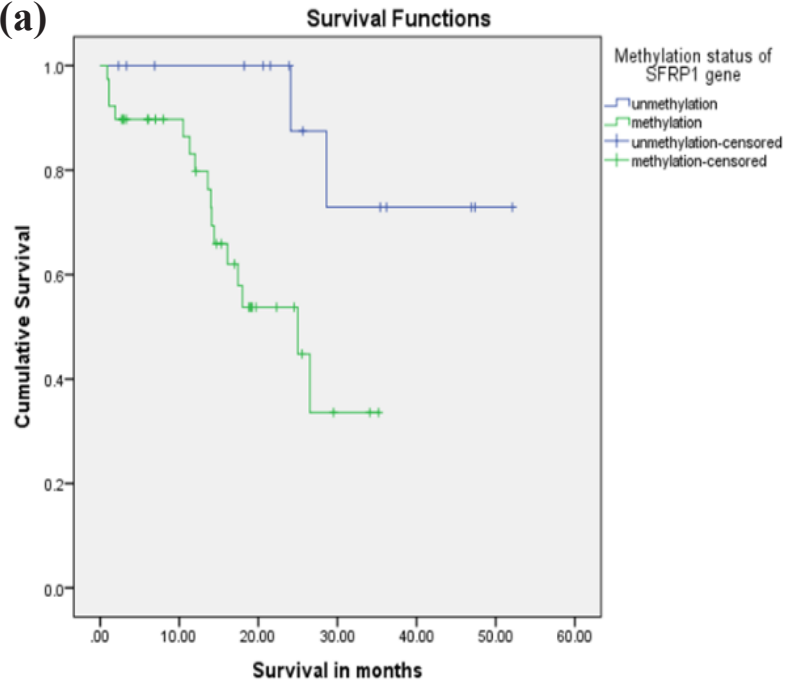

(b)

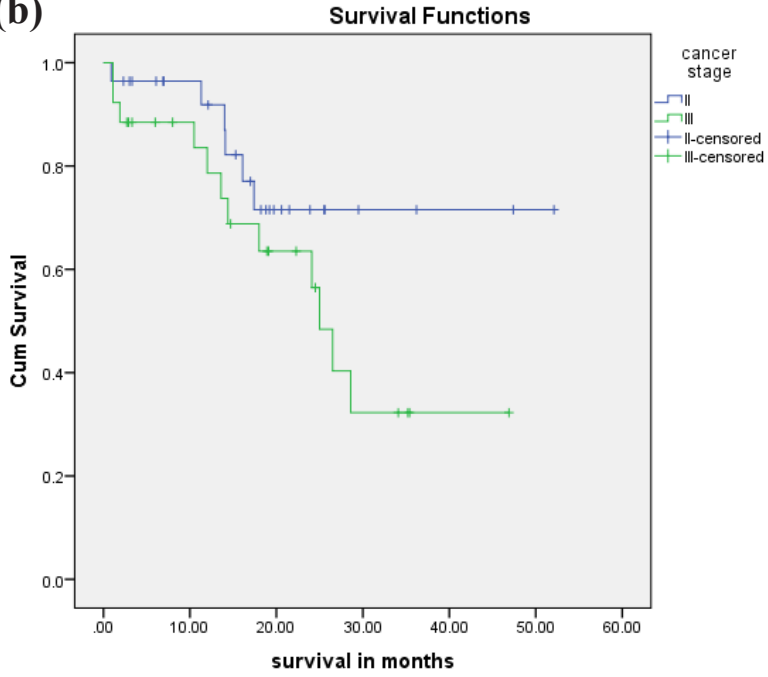

Figure 3. a, Kaplan-Meier survival analysis curve on the basis of methylation status of SFRP1 gene promoter region shows significance difference between methylated and un-methylated group $p=0.010$ (Log rank test); b, Kaplan-Meier survival analysis curve on the basis of clinical stage II vs III P=0.135.

2 out of $28(7 \%)$ cases adjacent non tumor tissue showed methylated SFRP1 gene. Thus a significant difference in methylation status $(\mathrm{P}<0.0001)$ was present between tumor and non-tumor tissue (Figure 1). Methylated in relation to clinical stage was noted in $60.7 \%$ cases of stage II and $84.6 \%$ cases of stage III tumor. To ascertain the methylation status of $\mathrm{CpG}$ sites present within promoter region of SFRP1 gene, we performed Bisulfite Sequencing of the $126 \mathrm{bp}$ DNA fragment of SFRP1 gene amplified by MS-PCR in representative cases. Bisulphite sequencing showed methylated Cytosine nucleotide in the CpG sites. This 126 bp DNA sequence, in the cases showing methylated SFRP1 in MS-PCR, contained 22 $\mathrm{CpG}$ cites within which most of the cytosine nucleotides were methylated (Figure 2).
SFRP1 promoter methylation associated with lymph node invasion

Promoter methylation status of SFRPI gene was compared with patient's clinicopathological characteristics such as age, gender, tumor location, lymph node involvement, tumor stage, and tumor grade (Table 1). Chi square test results show that lymph node metastasis was significantly associated with methylation status of SFRP1 gene in the tumor. Lymph node involvement (pN1-3) was noted in $84.6 \%$ cases with methylated SFRP1. Location of tumor was not associated with methylation status. A higher frequency of methylation was observed in patients over 60 years age, however this was not statistically significant.

Table 1. Clinicopathological Characteristics of CRC Cases and Their Association with Methylation

\begin{tabular}{|c|c|c|c|c|c|}
\hline \multirow[t]{2}{*}{ Variable } & \multirow[t]{2}{*}{ Categories } & \multirow[t]{2}{*}{ No. of cases } & \multicolumn{2}{|c|}{ Methylation status of $S F R P 1$ gene promoter } & \multirow[t]{2}{*}{$p$-value } \\
\hline & & & Un-methylated $n=15(27.8 \%)$ & Methylated $n=39(72.2 \%)$ & \\
\hline \multirow[t]{2}{*}{ Age group } & $<50$ year & 27 & $9(33.3)$ & $18(66.7)$ & \multirow[t]{2}{*}{0.54} \\
\hline & $>50$ year & 27 & $6(22.2)$ & $21(77.8)$ & \\
\hline \multirow[t]{2}{*}{ Gender } & Male & 33 & $8(24.2 \%)$ & $25(75.8 \%)$ & \multirow[t]{2}{*}{0.54} \\
\hline & Female & 21 & $7(33.3 \%)$ & $14(66.7 \%)$ & \\
\hline \multirow[t]{3}{*}{ Tumour Stage } & $\mathrm{T} 2$ & 9 & $3(33.3 \%)$ & $6(66.7 \%)$ & \multirow[t]{3}{*}{0.77} \\
\hline & $\mathrm{T} 3$ & 23 & $7(30.4 \%)$ & $16(69.9 \%)$ & \\
\hline & $\mathrm{T} 4$ & 22 & $5(22.7 \%)$ & $17(77.3 \%)$ & \\
\hline \multirow{2}{*}{$\begin{array}{l}\text { Lymph-node } \\
\text { involvement }\end{array}$} & $\mathrm{pN} 0$ & 28 & $11(39.3 \%)$ & $17(60.7 \%)$ & \multirow[t]{2}{*}{0.05} \\
\hline & $\mathrm{pN} 1-3$ & 26 & $4(15.4 \%)$ & $22(84.6 \%)$ & \\
\hline \multirow[t]{2}{*}{ Histological type } & Infiltrating adenocarcinoma NOS & 47 & $13(27.7 \%)$ & $34(72)$. & \multirow[t]{2}{*}{1} \\
\hline & Mucinous adenocarcinoma & 7 & $2(28.6 \%)$ & $5(71.4 \%)$ & \\
\hline \multirow[t]{3}{*}{ Tumour grade } & Poorly differentiated & 9 & $3(33.3 \%)$ & $6(66.7 \%)$ & \multirow[t]{3}{*}{0.83} \\
\hline & Moderately differentiated & 13 & $4(30.8 \%)$ & $9(69.2 \%)$ & \\
\hline & Well differentiated & 32 & $8(25 \%)$ & $24(75 \%)$ & \\
\hline \multirow[t]{2}{*}{ Tumour location } & Colon & 38 & $10(26.3)$ & $28(73.7)$ & \multirow[t]{2}{*}{0.747} \\
\hline & Rectum & 16 & $5(31.2 \%)$ & $11(68.8 \%)$ & \\
\hline
\end{tabular}

Table 1- Showing association of clinico-pathological parameters in relation to methylation status of SFRP1 gene using Chi square test (significant p-value $<0.05$ ). 
DOI:10.31557/APJCP.2019.20.5.1571

Prognostic Relevance of SFRP1 Gene Promoter Methylation in Colorectal Carcinoma

Table 2. Association between Clinicopathological Characteristics and Prognosis of the Disease by Using Univariate Cox Regression Analysis

\begin{tabular}{|c|c|c|c|c|c|}
\hline Variables & Categories & No. of cases & No of Events (deaths) & HR & 95\% CI\# (Lower-Upper) \\
\hline \multirow[t]{2}{*}{ Age group } & $<50$ year & 27 & 11 & 1 & Ref. \\
\hline & $>50$ year & 27 & 7 & 0.672 & $(0.183-2.475)$ \\
\hline \multirow[t]{2}{*}{ Gender } & Male & 33 & 13 & 1 & Ref. \\
\hline & Female & 21 & 5 & 0.308 & $(0.089-1.063)$ \\
\hline \multirow[t]{2}{*}{ Histological type } & Infiltrating adenocarcinoma NOS & 47 & 14 & 1 & Ref \\
\hline & Mucinous adenocarcinoma & 7 & 4 & 2.404 & $(0.664-8.701)$ \\
\hline \multirow[t]{3}{*}{ Tumor grade } & Poorly differentiated & 9 & 4 & 1 & Ref. \\
\hline & Moderately differentiated & 13 & 3 & 0.267 & $(0.042-1.681)$ \\
\hline & Well differentiated & 32 & 11 & 0.333 & $(0.082-1.356)$ \\
\hline \multirow[t]{3}{*}{ Tumor stage } & $\mathrm{pT} 2$ & 9 & 3 & 1 & Ref. \\
\hline & pT3 & 23 & 6 & 0.387 & $(0.075-1.982)$ \\
\hline & pT4 & 22 & 9 & 0.755 & $(0.144-3.955)$ \\
\hline \multirow[t]{2}{*}{ Tumor location } & Colon & 38 & 11 & 1 & Ref. \\
\hline & Rectum & 16 & 7 & 1.15 & $(0.391-3.385)$ \\
\hline \multirow{2}{*}{$\begin{array}{l}\text { Lymph node } \\
\text { involvement }\end{array}$} & $\mathrm{pN} 0$ & 28 & 6 & 1 & Ref. \\
\hline & $\mathrm{pN} 1-3$ & 26 & 12 & 1.281 & $(0.391-4.471)$ \\
\hline \multirow{2}{*}{$\begin{array}{l}\text { Methylation status of } \\
\text { SFRP1 gene promoter }\end{array}$} & Un-methylation & 15 & 2 & 1 & Ref. \\
\hline & Methylation & 39 & 16 & 17.313 & $(2.021-148.290)$ \\
\hline
\end{tabular}

HR, (Hazard Ratio); \#, Hazard Ratio (95\% Confidence Interval); Ref., taken as reference

Methylation of SFRP1 decreases the overall survival

Based on the observed methylation status of SFRP1 gene in the tumor tissue, methylated and unmethylated groups were defined. Follow-up in 54 patients ranging from 12 month to 56 month (median follow-up 28 months) $18 \mathrm{CRC}$ patients had died due to disease related event and advanced tumor stage and 12 patients lost to follow-up. The overall mean survival of unmethylated and methylated group was 45.173 months and 22.318 months respectively survival curve in (Figure $3 a)$. The combined estimated OS of both the groups were 33.461 months. Unmethylated groups survival was significantly better as compare to methylated group ( $p=0.010$ by Log rank test) and poor survival associated with methylation of SFRP1. We also analyzed survival of CRC patients with reference of 8 deferent conventional pathological factors such as Age group, Gender, Tumor stage, Clinical stage, Lymph node status, Differentiation of tumor and Tumor subtype (Table 3). Kaplan-Meir survival analysis results shows survival is dependent on many factors but it was majorly influenced by lymph node status and methylation of SFRP1. If we talk about survival on the basis of clinical

Table 3. Kaplan-Meier Survival Analysis with References to Clinicopathological Characteristics.

\begin{tabular}{|c|c|c|c|c|c|}
\hline Variables & Categories & No. of cases & No of Events (death) & Mean Survival in months & $P$ value \\
\hline \multirow{2}{*}{$\begin{array}{l}\text { Methylation status of } \\
\text { SFRP1 }\end{array}$} & Un-methylation & 15 & 2 & 45.17 & 0.01 \\
\hline & methylation & 39 & 16 & 22.32 & \\
\hline \multirow[t]{2}{*}{ Age group } & $>50$ year & 27 & 7 & 34.68 & 0.472 \\
\hline & $<50$ year & 27 & 11 & 28.66 & \\
\hline Lymph-node & $\mathrm{pN} 0$ & 28 & 6 & 40.96 & 0.135 \\
\hline involvement & $\mathrm{pN} 1-3$ & 26 & 12 & 26.88 & \\
\hline \multirow[t]{2}{*}{ Gender } & Male & 33 & 13 & 29.34 & 0.146 \\
\hline & Female & 21 & 5 & 29.75 & \\
\hline \multirow[t]{3}{*}{ Tumour grade } & Poorly differentiated & 7 & 3 & 27.10 & 0.68 \\
\hline & Moderately differentiated & 14 & 4 & 29.33 & \\
\hline & Well differentiated & 26 & 7 & 32.78 & \\
\hline \multirow[t]{3}{*}{ Tumour stage } & pT2 & 9 & 3 & 26.99 & 0.284 \\
\hline & pT3 & 23 & 6 & 37.81 & \\
\hline & pT4 & 22 & 9 & 18.95 & \\
\hline \multirow[t]{2}{*}{ Histological type } & Infiltrating adenocarcinoma NOS & 47 & 14 & 34.70 & 0.142 \\
\hline & Mucinous adenocarcinoma & 7 & 4 & 24.85 & \\
\hline \multirow[t]{2}{*}{ Location of tumour } & Colon & 38 & 11 & 26.17 & 0.931 \\
\hline & Rectum & 16 & 7 & 34.06 & \\
\hline
\end{tabular}


stage II and III the mean survival was 40.96 and 26.88 months respectively $\mathrm{p}=0.135$ by $\log$ rank test (Figure $3 b$ ). To explore the contribution of these variables and evaluation of their influence as potential prognostic marker, all these variables were analyzed by univariate cox regression model analysis. In univariate analysis, only SFRP1 methylation status could be verified as an independent prognostic factor, $(\mathrm{HR}=17.313,95 \% \mathrm{CI}$ : 2.021-148.290, and $P$-value $=0.009$, Table 2). Univariate cox model suggesting, among these variables, SFRP1 methylation can serve as an independent prognostic indicator of poor survival in CRC.

\section{Discussion}

Wnt signaling plays important role in embryonic development where it determines the cell fate, cell proliferation and cell migration (Clevers and Hans, 2006; Zhan et al. 2016). In life, Wnt signaling also controls tissue regeneration in adult bone marrow, skin and intestine (Goessling et al., 2009). Wnt signaling maintains intestinal stem cells by proliferation and differentiation. It is also involved in carcinogenesis of various tumors including CRC (Mii and Taira, 2011; Zhan et al., 2016; Zhou et al., 2015; Clevers and Hans, 2006; Huang et al., 2006). SFRP1 gene is known for its ability to negatively modulate the $\mathrm{Wnt} / \beta$-catenin signaling cascade. Promoter methylation downregulates the expression of SFRP1 gene in CRC (Jones and Jomary, 2002; Suzuki et al., 2004; Shih et al., 2006, Fukui et al., 2005) Silencing of SFRP1 gene, allows constitutive WNT signaling via binding to Wnt protein and inhibits its binding to Wnt-frizzled receptor, consequently altering the proliferation and differentiation of tumor cells. Limited studies have looked in to the association of SFRP1 methylation with clinicopathological characters and survival in CRC. Studies done on other tumors suggest that methylation of SFRPl gene can serve as epigenetic diagnostic, prognostic and predictive marker in liver, gall bladder, upper gastrointestinal tract and lung cancers (Kim et al., 2016; Mo et al., 2018; Suzuki et al., 2002; Müller et al., 2004; Zou et al., 2005; Su et al., 2009) In the present study, we have studied promoter methylation status of SFRP1 gene in CRC patients and its association with various clinicopathological characteristics. We found that SFRP1 was frequently methylated in tumor tissue compared with adjacent non tumor tissues. The frequency of SFRP1 gene promoter methylation in our patients was $72.2 \%$. Previous studies, have shown a frequency ranging from $52-95 \%$ in colorectal cancer (Rawson et al., 2011; Barták, 2017; Zhou et al., 2015; Meng et al., 2011; Dallol et al., 2012; Salehi et al., 2012). In present study we noted a slightly higher incidence of hypermethylation of SFRP1 in male patients than females (75.8\% vs. 66.7\%), however this difference was not statistically significant $(\mathrm{p}=0.54)$. The frequency of methylation was not influenced by the histological subtype of tumor. Infiltrating adenocarcinoma NOS and mucinous adenocarcinoma showed SFRP1 gene promoter methylation frequency of $72.3 \%$ and $71.4 \%$ respectively. In $84 \%$ cases with lymph node metastasis, SFRP1 gene methylation was noted which was significant $(\mathrm{P}=0.05)$.
Other clinicopathological characters such as age, gender, tumor, location, tumor stage, tumor type, grade of tumor did not show any significant association with methylation status of SFRP1 gene. Our data suggests that SFRP1 promoter methylation is an epigenetic prognostic marker for poor survival in stage II and III CRC. The patients in the methylated group had shorter mean overall survival (22.318 months) as compared to the un-methylated group (45.173 months). A possible reason for shorter overall survival with methylated SFRPI gene in CRC could be that promoter methylation reduces expression of SFRP1 gene allowing constitutive WNT signaling that may help tumor cell to proliferate. Epigenetic inactivation of SFRP genes allowing constitutive WNT signaling in colorectal cancer has been previously described by Suzuki et al., (2004). SFRPl gene has also been studied in other tumors such as Head and neck squamous Cell carcinoma, breast cancer and found to indicate poor patients survival (Alsofyani et al., 2016, Veeck et al., 2008, Kang et al., 2014) An implication of this findings can also be explored for targeted therapy in CRC using recombinant SFRP1 (Cooper et al., 2012).

This study has some limitations such as smaller sample size and shorter duration of follow-up. However even then the findings obtained are important with prognostic significance. Similar studies with larger sample size and longer follow-up would be helpful to substantiate our findings.

In conclusion our study shows that promoter methylation of SFRP1 gene occurs frequently in Colorectal Carcinoma. This SFRP1 promoter methylation is significantly associated with lymph node invasion and poor survival outcome in stage II and III CRC patients and it appears to be a poor prognostic marker.

\section{Acknowledgments}

The authors wish to thank Mr. Manoj Pandey who helped in statistical analysis. The authors would also like to thank the funding agencies, University Grant commission (UGC), New Delhi, India, for UGC-NonNet fellowship-2013-17 and UGC, National fellowship for SC (RGNF) - ( F1-17.1-2017-18/RGNF-2017-18-SCUTT-30798) for Mr. Alok Kumar.

\section{References}

Alsofyani AA, Alsiary RA, Samkari A, et al (2017). Prognostic potential of KLOTHO and SFRP1 promoter methylation in head and neck squamous cell carcinoma. J Appl Genet, $\mathbf{5 8 ,} 459-65$.

Armaghany T, Wilson JD, Chu Q, Mills G (2012). Genetic alterations in colorectal cancer. Gastrointestinal Cancer Res, 1, 19.

Barták BK, Kalmár A, Péterfia B, et al (2017.) Colorectal adenoma and cancer detection based on altered methylation pattern of SFRP1, SFRP2, SDC2, and PRIMA1 in plasma samples. Epigenetics, 12, 51-63.

Bray F, Ferlay J, Soerjomataram I, et al (2018). Global cancer statistics 2018, 2018GLOBOCAN estimates of incidence and mortality worldwide for 36 cancers in 185 countries. CA Cancer J Clin, 68, 394-424. 
Clevers H (2006). Wnt/ $\beta$-catenin signaling in development and disease. Cell, 127, 469-80.

Colussi D, Giovanni B, Franco B, Luigi R (2013). Molecular pathways involved in colorectal cancer: implications for disease behavior and prevention. Int J Mol Sci, 14, 16365-85.

Cooper SJ, Von Roemeling CA, Kang KH, et al (2012). Reexpression of tumor suppressor, $s F R P 1$, leads to antitumor synergy of combined HDAC and methyltransferase inhibitors in chemoresistant cancers. Mol Cancer Ther, 11, 2105-15.

Dallol A, Al-Maghrabi J, Buhmeida A, et al (2012). Methylation of the polycomb group target genes is a possible biomarker for favorable prognosis in colorectal cancer. Cancer Epidemiology and Prevention Biomarkers, 21, 2069-75.

Fearon ER, Vogelstein B. (1990). A genetic model for colorectal tumorigenesis. Cell, 61, 759-67.

Fukui T, Kondo M, Ito G, et al (2005). Transcriptional silencing of secreted frizzled related protein 1 (SFRP1) by promoter hypermethylation in non-small-cell lung cancer. Oncogene, 41,6323

Goessling W, North TE, Loewer S, et al (2009). Genetic interaction of PGE2 and Wnt signaling regulates developmental specification of stem cells and regeneration. Cell, 136, 1136-47.

Herman James G, Jeremy R, Graff SBDN, et al (1996). Methylation-specific PCR: a novel PCR assay for methylation status of $\mathrm{CpG}$ islands. Proc Natl Acad Sci $U S A, 93,9821-6$.

Huang ZH, Li LH, Yang F, Wang JF (2006). Detection of aberrant methylation in fecal DNA as a molecular screening tool for colorectal cancer and precancerous lesions. World $J$ Gastroenterol, 13, 950.

Jones SE, Jomary C (2002). Secreted frizzled-related proteins: searching for relationships and patterns. Bioessays, 24, 811-20.

Kang P, Wan M, Huang P, et al (2014). The Wnt antagonist $s F R P 1$ as a favorable prognosticator in human biliary tract carcinoma. PLoS One, 9, e90308.

Kim DC, Kim KU, Kim YZ (2016). Prognostic role of methylation status of the MGMT promoter determined quantitatively by pyrosequencing in glioblastoma patients. J Korean Neurosurg Soc, 59, 26.

Leygo C, Williams M, Jin HC, et al (2017). DNA methylation as a noninvasive epigenetic biomarker for the detection of cancer. Dis Markers, 2017, 1-13.

Lippincott-R (1998). American Joint Committee on Cancer, AJCC Cancer Staging Manual, 5th ed. Philadelphia: Lippincott-Raven; 1998

Meng Y, Wang QG, Wang JX, et al (2011). Epigenetic inactivation of the SFRPl gene in esophageal squamous cell carcinoma. Dig Dis Sci, 56, 3195-203

Mii Y, Taira M (2011). Secreted Wnt "inhibitors" are not just inhibitors: regulation of extracellular Wnt by secreted frizzled-related proteins. Dev Growth Differ, 53, 911-23.

Mo S, Su Z, Heng B, et al (2018). SFRPl promoter methylation and renal carcinoma risk: A systematic review and meta-analysis. J Nippon Med Sch, 85, 78-86.

Müller HM, Oberwalder M, Fiegl H, et al (2004). Methylation changes in faecal DNA: a marker for colorectal cancer screening?. Lancet, 363, 1283-5.

Nandakumar V, Vaid M, Tollefsbol TO, Katiyar SK (2011). Aberrant DNA hypermethylation patterns lead to transcriptional silencing of tumor suppressor genes in UVB-exposed skin and UVB-induced skin tumors of mice. Carcinogenesis, 32, 597-604.

Novellasdemunt L, Antas P, Li VS (2015). Targeting Wnt signaling in colorectal cancer. A review in the theme: cell signaling: proteins, pathways and mechanisms. Am J Physiol Cell Physiol, 309, 511-21.

Rawson JB, Manno M, Mrkonjic M, et al (2011). Promoter methylation of Wnt antagonists DKK1 and SFRP1 is associated with opposing tumor subtypes in two large populations of colorectal cancer patients. Carcinogenesis, 32, 741-7.

Salehi R, Mohammadi M, Emami MH, Salehi AR (2012). Methylation pattern of SFRP1 promoter in stool sample is a potential marker for early detection of colorectal cancer. Adv Biomed Res, 1, 1-87.

Shih YL, Shyu RY, Hsieh CB, et al (2006). Promoter methylation of the secreted frizzled-related protein 1 gene SFRP1 is frequent in hepatocellular carcinoma. Cancer, 107, 579-90.

Su HY, Lai HC, Lin YW, et al (2009). An epigenetic marker panel for screening and prognostic prediction of ovarian cancer. Int J Cancer, 124, 387-93.

Susan JC, Harrison J, Paul CL, Frommer M (1994). High sensitivity mapping of methylated cytosines. Nucleic Acids Res, 22, 2990-7.

Suzuki H, Gabrielson E, Chen W, et al (2002). A genomic screen for genes upregulated by demethylation and histone deacetylase inhibition in human colorectal cancer. Nat Genet, 31, 141-9.

Suzuki H, Watkins DN, Kam-Wing J, et al (2004). Epigenetic inactivation of SFRP genes allows constitutive WNT signaling in colorectal cancer. Nat Genet, 36, 417.

Takada T, Yagi Y, Maekita T, et al (2004). Methylation-associated silencing of the Wnt antagonist SFRP1 gene in human ovarian cancers. Cancer Sci, 95, 741-4.

Thiel A, Ari R (2013). Toward a molecular classification of colorectal cancer: The role of BRAF" frontiers in oncology vol. 3 281., doi:10.3389/fonc.2013.00281

Veeck J, Geisler C, Noetzel E, et al (2008). Epigenetic inactivation of the secreted frizzled-related protein-5 (SFRP5) gene in human breast cancer is associated with unfavorable prognosis. Carcinogenesis, 29, 991-8.

Weller M, Stupp, R, Reifenberger, et al (2010). MGMT promoter methylation in malignant gliomas: ready for personalized medicine?. Nat Rev Neurol, 6, 39.

Wheeler JMD, Bodmer WF, Mortensen NM (2000). DNA mismatch repair genes and colorectal cancer. Gut, 47, 148-53.

Zhan T, Rindtorff N, Boutros M (2016). Wnt signaling in cancer. Oncogene, 36, 1461-73.

Zheng L, Sun D, Fan W, et al (2015). Diagnostic value of $S F R P 1$ as a favorable predictive and prognostic biomarker in patients with prostate cancer. PLoS One, 10, e0118276.

Zhou S, Flamier A, Abdouh M, et al (2015). Differentiation of human embryonic stem cells into cone photoreceptors through simultaneous inhibition of BMP, TGF $\beta$ and Wnt signaling. Development, 142, 3294-3306.

Zou H, Molina JR, Harrington JJ,et al (2005) Aberrant methylation of secreted frizzled-related protein genes in esophageal adenocarcinoma and Barrett's esophagus. Int $J$ Cancer, 116, 584-91.

This work is licensed under a Creative Commons AttributionNon Commercial 4.0 International License. 